\title{
LAS COMPLICACIONES EN EL EJERCICIO ACTUAL DE LA MEDICINA EN COLOMBIA
}

a delegación de la atención en salud de los ciudadanos por parte del Estado a los particulares (Ley 100 de 1993) por medio de las compañías aseguradoras en salud, tales como las empresas prestadoras de servicios de salud (EPS), compañías de medicina prepagada y administradoras del régimen subsidiado (ARS) ha generado grandes cambios en el ejercicio de la actividad médica.

Con profunda preocupación en la actualidad somos testigos de una nueva interpretación del ejercicio médico por parte de las compañías aseguradoras.

Según esta interpretación, en los contratos de prestación de servicios asistenciales para personas naturales de algunas entidades de medicina prepagada reza lo siguiente: "En consideración a que el Profesional o Prestador en ejercicio de su actividad se encuentra plenamente facultado para sugerir e indicarle al usuario lo que a su criterio considere como procedimiento adecuado, el Profesional o Prestador acepta en forma expresa informar y responder al usuario en forma íntegra y exclusiva sin excepción por todas las consecuencias que cualquier acto u omisión suyos o de sus dependientes, genere durante el proceso de atención y la prestación de sus servicios, sin intervenir e inferir en la interpretación de los planes de beneficios de la entidad "Empresa aseguradora", en virtud de lo anterior la "Empresa aseguradora" no asume ninguna responsabilidad imputable por este concepto y así lo acepta expresamente el Profesional o Prestador".

Al leer el párrafo anterior surgen las siguientes preguntas. ¿Qué significa responder al usuario por las consecuencias de cualquier acto durante el proceso de y la prestación de sus servicios? ¿Incluye las complicaciones? ¿Quién será el responsable de calificar la omisión? ¿Qué normas de manejo, protocolos o guías servirán de base para calificar la omisión? ¿Qué implicaciones patrimoniales tiene para el médico el que la compañía aseguradora no asuma ninguna responsabilidad imputable por concepto de las consecuencias de cualquier acto en la prestación del servicio?

Antes de firmar este tipo de contratos los médicos debemos reflexionar profundamente acerca de las implicaciones que conlleva su aceptación.

Veamos el caso de las complicaciones médicoquirúrgicas. El "Diccionario de la Lengua Española de la Real Academia Española" define la palabra complicación. (Del lat. complicatio, -ônis, plegadura), como la acción y efecto de complicar, la dificultad o enredo procedentes de la concurrencia y encuentro de cosas diversas, o también como complejidad. En cuanto a complicación médica el "Medical Dictionary Search Engine" define la complicación médica como: un término utilizado para describir problemas médicos adicionales que se desarrollan después de un procedimiento, tratamiento o enfermedad. Las complicaciones por lo general están directa o indirectamente relacionadas con un procedimiento, conocido como riesgo del procedimiento, a un tratamiento conocido como efecto colateral o toxicidad, o se presentan en el curso de una en- 
fermedad como parte de su historia natural o de su curso clínico.

Tenemos entonces que las complicaciones pueden ser el resultado de la enfermedad de base, como sería la aparición de la insuficiencia cardiaca en un paciente con hipertensión arterial. También pueden surgir como dificultad en un acto quirúrgico o posterior a él. Sería la situación que se presenta en la infección puerperal o infección de la herida quirúrgica después de una cirugía o luego de un procedimiento, como sería la muerte fetal posterior a una amniocentesis.

El problema de las complicaciones médicas es determinar si se puede predecir su aparición o qué tanto se puede prevenir su aparición y desarrollo. Este problema es posible abordarlo desde dos puntos de vista: el del médico y el del derecho médico.

Desde el punto de vista médico la aparición de una complicación se puede parcialmente predecir mediante la estimación del riesgo. Desde el punto de vista epidemiológico, se tienen estimadores tales como: las tasas de mortalidad y de morbilidad, el riesgo relativo (RR), la razón de oportunidades (OR), el número necesario para dañar (NND), el incremento absoluto o relativo del riesgo, por medio de los cuales se intenta hacer una aproximación de qué tan probable es que se presente una complicación o qué tantas veces es más probable que se desarrolle la misma dado que se padece previamente una enfermedad, o se ha estado expuesto a una sustancia que podría ser un medicamento en el caso de los eventos adversos. Sin embargo, es solo una aproximación, por lo tanto la predicción puede fallar dando falsos positivos o falsos negativos en un importante número de $\mathrm{Ca}-$ sos, dependiendo de la patología de base y del procedimiento que se va a realizar.

Como ejemplo de una complicación frecuente, se conoce que la tasa de mortalidad de los pacientes con angina inestable e infarto de miocardio es del
2.5\% y morirán en las primeras 24 horas, a pesar de la aplicación del tratamiento correcto. De este modo se podrá predecir que el 2.5\% de los pacientes morirá en este periodo; sin embargo, no se podrá predecir puntualmente en cada paciente la probabilidad de muerte. Hay situaciones todavía más difíciles de predecir, como la aparición de eclampsia en una paciente con hipertensión inducida por el embarazo.

Por otra parte, en cuanto a la prevención de las complicaciones se podrá minimizar el riesgo de que estas aparezcan, haciendo una buena historia clínica para la detección de comorbilidades o condiciones asociadas para tratar, por medio de la selección del tratamiento adecuado y una técnica depurada en las intervenciones quirúrgicas, el reconocimiento de las limitaciones en el entrenamiento y una vigilancia estricta durante el tratamiento o posterior al procedimiento. Pero no se podrá excluir del todo, a pesar de las diferentes medidas, que aparezca una complicación, por ejemplo, una hemorragia posparto o una lesión de vejiga en una histerectomía.

Por último, vale la pena recordar que hay complicaciones que no son previsibles ni predecibles como el embolismo amniótico asociado con una altísima mortalidad materna.

Desde el punto de vista del derecho médico y partiendo del hecho, según el cual al médico lo alienta en su intención el beneficio a su paciente, se busca establecer si hay culpa ante la presencia de la complicación. La culpa se podrá calificar como negligencia (no hacer), impericia (no saber hacer), la imprudencia (hacer sin saber) o la violación de reglamentos. Los preceptos que deben dirigir el actuar médico están contenidos en el Código de Ética Médica, Ley 23 de 1981. En este código están claramente establecidas las obligaciones del médico en cuanto a: el secreto profesional, la información adecuada y el consentimiento, la obligación del conocimiento, la obligación de diligencia y técnica, la continuidad del tratamiento, 
la asistencia y consejo, la certificación de enfermedad y del tratamiento efectuado. También establece el concepto de riesgo previsto, que sería determinado a partir de los indicadores epidemiológicos antes mencionados.

El estricto seguimiento del Código de Ética garantizará la defensa del médico ante los tribunales éticos, civiles y penales.

Pero una cosa es que un paciente o sus familiares ante la gravedad de una complicación y como parte de la elaboración del duelo o mal aconsejados por un abogado con intereses monetarios, quiera llevar al médico ante un tribunal para que responda patrimonialmente por el mal resultado, y otra cosa es que nosotros mismos los médicos asumamos de manera espontánea que las complicaciones son siempre culpa nuestra, como resultado de la impericia, negligencia o imprudencia, como lo sugieren los contratos de prestación de servicios antes mencionados.

Claro está que en teoría nadie nos obliga a firmar estos contratos y somos libres de rescindir la prestación de servicios a los usuarios de estas compañías; sin embargo, las aseguradoras se aprovechan de las presiones sociales, como alto desempleo médico, baja remuneración salarial, distorsión de la relación médico-paciente por la nueva relación paciente - aseguradora - médico, para que los colegas firmen dichos contratos.

Conviene recordarles a las aseguradoras que pretenden la firma de estos contratos, que así como hay una Ética Médica también hay una Ética Empresarial. Que la ética o el deber ser, se centra en el trato que damos a las personas que nos rodean y como nos comportamos. Esto incluye amabilidad, interés, respeto, justicia y sinceridad. La esencia de los negocios no debe tomarse nunca como un intento de pasar el dinero del bolsillo de otros al nuestro. Tiene que considerarse un arte de rendimiento, la creación y el cuidado de unas estructuras, en el seno de las cuales la gente pueda unirse en asociaciones para el bienestar. A las personas les gusta trabajar en empresas que representen algo en las que ellas creen, algo noble y bueno.

En la actualidad en muchos países los empresarios son responsables de sus propios actos ante la sociedad, los consumidores y frente al Estado, como es el caso de los recientes ejemplos de las empresas Enron o World.com. Cabe recordar que las empresas no solo deben velar por los beneficios de sus accionistas, sino que también tienen una responsabilidad social ante los proveedores, sus socios (en este caso los médicos), los consumidores (los pacientes) y la sociedad en general.

Así como en la actualidad se cuestiona frecuentemente el acto médico, también se debe hacer lo mismo con el acto empresarial de compañías que lo único que buscan es bajar los costos para aumentar la rentabilidad, mediante trabas administrativas que impiden dar una atención rápida, segura y eficiente a los usuarios, y que además van en contra de sus socios comerciales y los médicos al no respetar lo establecido por el Artículo 7 de la Ley de Ética Médica: "El médico tiene derecho a recibir remuneración por su trabajo, la cual constituye su medio normal de subsistencia. Es entendido que el trabajo o servicio del médico sólo lo beneficiará a él y a quien lo reciba. Nunca a terceras personas que pretendan explotarlo comercial o políticamente”. O que inducen bajo presiones de tipo laboral a los médicos para que no hagan respetar el Artículo 10 de la misma Ley que establece: "El médico dedicará a su paciente el tiempo necesario para hacer una evaluación adecuada de su salud e indicará los exámenes indispensables para precisar el diagnóstico y prescribir la terapéutica correspondiente”. Todo esto ante la mirada complaciente de las entidades reguladoras del Estado y de los gobernantes de turno, que más bien parecen indolentes ante la realidad antes que reconocer sus errores en la reglamentación de las leyes que han dado origen a estas situaciones.

Creo colegas que por el miedo a perder un contrato que brinda unos honorarios profesionales, 
en algunos casos importantes, se está poniendo en riesgo nuestro patrimonio, no solo el personal sino el familiar. Quién puede garantizar que en la atención de un parto no se presenten complicaciones serias como una sepsis puerperal o una hemorragia posparto o la eclampsia, complicaciones que podrán ser consideradas evitables desde el punto de vista institucional, pero por las cuales, según lo establecido en los contratos antes mencionados, serán responsabilidad nuestra no solo desde el punto de vista médico (responsabilidad a la que no rehusamos) sino monetaria. Cuánto puede costar una paciente de cinco días en cuidados intensivos para el manejo de una de las complicaciones antes mencionadas, que puede incluir costos de cirugías como histerectomías, lavados peritoneales, etc.

Creo que esta situación amerita una profunda reflexión acerca de las condiciones actuales del ejercicio médico, ante la falta de respeto de nosotros mismos por lo que hacemos, de las compañías aseguradoras, del Estado por la labor que realizamos y, sobre todo sugiero leer cuidadosamente y considerar los riesgos y beneficios de un contrato de prestación de servicios de las características mencionadas, antes de su firma.

Hernando Gaitán, M.D.

Editor 